Laser Chem., 1999, Vol. 19, pp. $201-208$

Reprints available directly from the publisher Photocopying permitted by license only
(C) 1999 OPA (Overseas Publishers Association) N.V. Published by license under the Harwood Academic Publishers imprint, part of The Gordon and Breach Publishing Group.

\title{
TIME-RESOLVED RESONANCE RAMAN STUDIES OF RADICALS FROM 4-AMINORESORCINOL AS MODELS FOR THE ACTIVE SITE RADICAL INTERMEDIATE IN COPPER AMINE OXIDASES
}

\author{
ROGER H. BISBY ${ }^{\mathrm{a}, *}$, STEVEN A. JOHNSON ${ }^{\mathrm{a}}$, \\ ANTHONY W. PARKER ${ }^{b}$ and SUSAN M. TAVENDER ${ }^{b}$

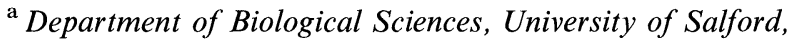 \\ Salford M5 4WT, UK; \\ ${ }^{\mathrm{b}}$ Lasers for Science Facility, Rutherford Appleton Laboratory, \\ Oxon $O X 110 Q X, U K$
}

(Received 30 April 1997)

Radicals formed by one-electron oxidation of 4-aminoresorcinol have been studied as models for the active site free radical intermediate which forms as a stable product during anaerobic incubation of amine oxidases with amine substrates. Pulse radiolysis shows that the radical undergoes ionisations with $\mathrm{pK}_{\mathrm{a}}$ 's of 3.4 and 6.4. Although the two deprotonated forms are difficult to distinguish by absorption spectroscopy, they have clearly different resonance Raman spectra. Comparison with the resonance Raman spectrum of the enzyme intermediate shows it to be the singly deprotonated form of the radical.

Keywords: Resonance Raman; enzyme; amine oxidase; free radical; aminoresorcinol; spectroscopy

The trihydroxyphenylalanine (TOPA) quinone residue at the catalytic site of copper amine oxidases is a recently discovered enzyme cofactor formed from post-translational modification of a tyrosine residue [1, 2]. The copper amine oxidases belong to the group of protein-radical

*Corresponding author. Tel.: 0161745 54912, e-mail: r.h.bisby@biosci.salford.ac.uk 
enzymes in which the catalytic mechanisms each involve a free radical site in the protein [3]. In the case of copper amine oxidases the TOPA quinone residue is reduced by substrate to a free radical, believed to be a TOPA-derived semi-iminoquinone $[4,5]$ whilst a cupric ion, serving as a second redox site, is simultaneously reduced to $\mathrm{Cu}(\mathrm{I})[6]$ as shown in Scheme 1 (adapted from Ref. [10]). In the X-ray crystal structures

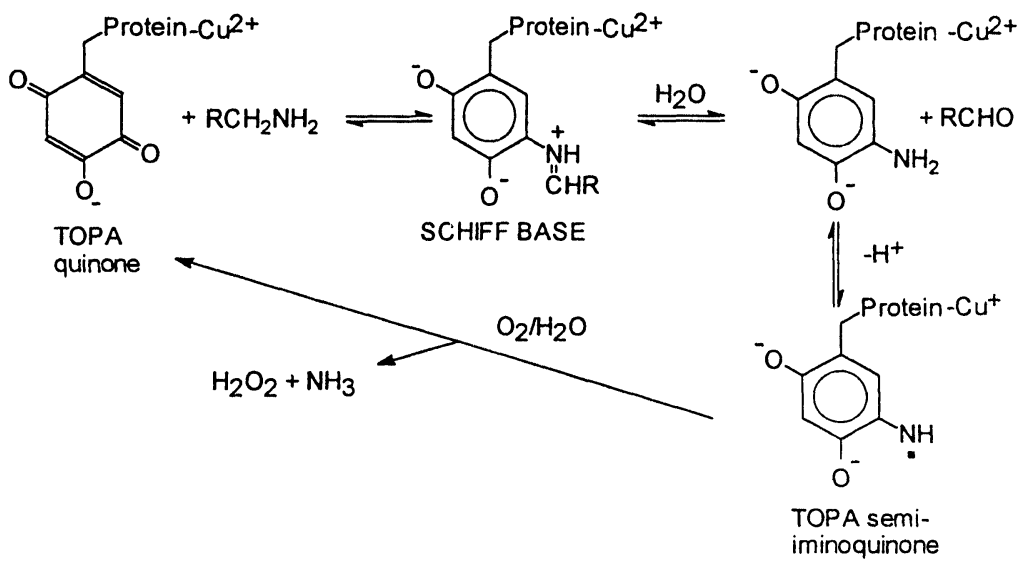

SCHEME 1

obtained recently for E. coli [7] and pea seedling [8] copper amine oxidases the TOPA quinone site is within about $6 \AA$, but is not a ligand, of the copper atom.

Several previous studies $[6,9,10]$ have reported the formation of a stable absorption with $\lambda_{\max }$ ca. $464 \mathrm{~nm}$ upon anaerobic incubation of copper amine oxidases with amine substrate. This rapidly disappears upon admission of oxygen with a second order constant [11] of $2.5 \times 10^{7} \mathrm{dm}^{3} \mathrm{~mol}^{-1} \mathrm{~s}^{-1}$. The resonance Raman spectrum of this intermediate has been measured using both ${ }^{14} \mathrm{~N}$ - and ${ }^{15} \mathrm{~N}$-containing substrates $[5,12]$. Small changes in the frequencies of some modes indicate incorporation of the nitrogen atom from substrate into the intermediate and identify it as a semi-iminoquinone. The formation of the enzyme radical and cuprous atom appears to be a mechanism to activate reduction of dioxygen [13]. The TOPA-semi-iminoquinone/ $\mathrm{Cu}(\mathrm{I})$ intermediate is in equilibrium with the fully reduced aminoquinol/ $\mathrm{Cu}(\mathrm{II})$ form [6]. 
4-Aminoresorcinol (4-AR) therefore serves as a model for the twoelectron reduced form of the TOPA quinone in the enzyme. Ground state $\mathrm{pK}_{\mathrm{a}}$ 's of 6-amino-4-ethylresorcinol have been determined [14], showing the 4-hydroxyl group of TOPA quinone to be ionised in active copper amine oxidase.

Free radicals which might serve as models for the protein-radical site in copper amine oxidases have been generated by one-electron oxidation of 4-AR in both pulse radiolysis and time-resolved resonance Raman $\left(\mathrm{TR}^{3}\right)$ experiments. In the pulse radiolysis experiments either $\mathrm{Br}_{2}^{-}$or $\mathrm{N}_{3}^{-}$radicals were used as one-electron oxidants. Transient absorption spectra of 4-AR radicals obtained between $\mathrm{pH} 1.9$ and $\mathrm{pH} 7.8$ are shown in Figure 1. At pH 1.9 the long wavelength absorption maximum is at $430 \mathrm{~nm}$, whereas at the two

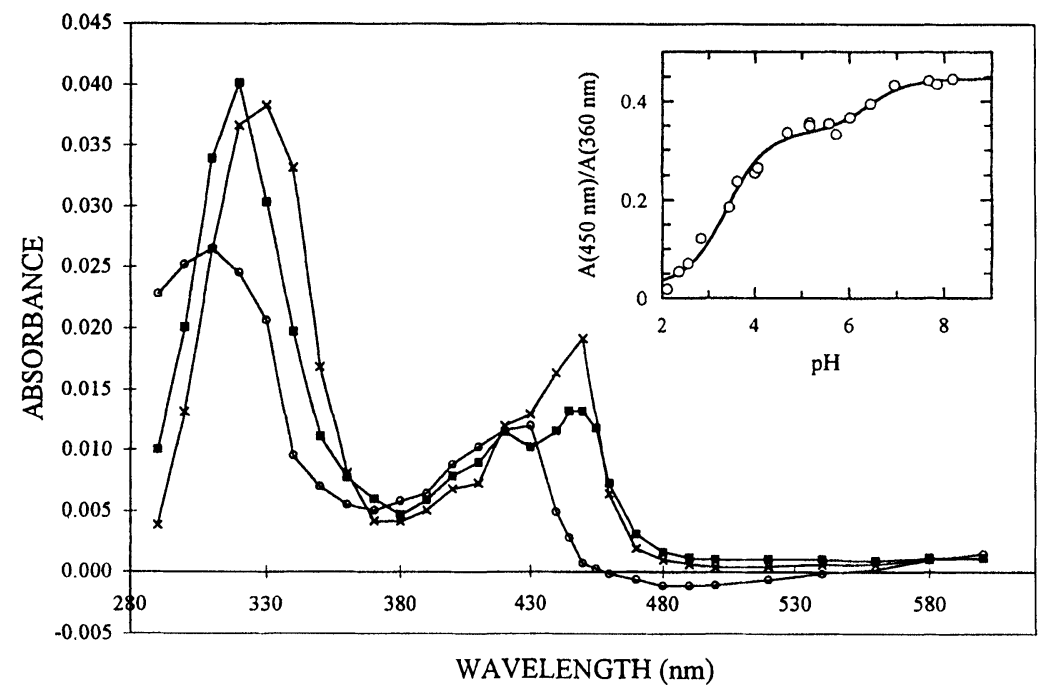

FIGURE 1 Transient spectra generated from one-electron oxidation of 4-aminoresorcinol (4-AR) by pulse radiolysis. Spectra were obtained in $\mathrm{N}_{2} \mathrm{O}$-saturated aqueous solutions at (a) $\mathrm{pH} 1.9$ in solutions containing 4-AR $(2 \mathrm{mM})$ and $\mathrm{KBr}(0.1 \mathrm{M})$, measured $65 \mu$ s after the pulse $(\mathrm{O}-\mathrm{O})$; (b) $\mathrm{pH} 6.0$ in solutions containing 4-AR $(0.25 \mathrm{mM})$ and $\mathrm{NaN}_{3}(0.1 \mathrm{M})$, measured $20 \mu$ s after the pulse $(\mathbf{\square}-\mathbf{a})$; and (c) $\mathrm{pH} 7.7$ in solutions containing 4-AR $(0.1 \mathrm{mM})$ and $\mathrm{NaN}_{3}(0.1 \mathrm{M})$, measured $20 \mu$ s after the pulse $(\mathrm{X}-\mathrm{X})$. $\mathrm{N}_{2} \mathrm{O}$ was used to convert the hydrated electron to hydroxyl radical, which was then scavenged by the $\mathrm{Br}^{-}$or $\mathrm{N}_{3}^{-}$. INSET:- effect of $\mathrm{pH}$ on the transient absorbance of 4-AR radicals at $450 \mathrm{~nm}$, formed by oxidation with $\mathrm{Br}_{2}^{-}$, normalised to the $\mathrm{Br}_{2}^{-}$radical absorbance at $360 \mathrm{~nm}$ immediately after the pulse. 
higher $\mathrm{pH}$ values this shifts to $450 \mathrm{~nm}$. At $\mathrm{pH} 6.0$ and 7.8 the spectra are somewhat similar, although the extinction coefficient is slightly increased at the higher $\mathrm{pH}$ with a value of approximately $5 \times 10^{3} \mathrm{M}^{-1} \mathrm{~cm}^{-1}$. A plot of transient absorbance at $450 \mathrm{~nm}$ as a function of $\mathrm{pH}$ is shown as the inset to Figure 1. The data are best fit to a double $\mathrm{pK}$ curve with $\mathrm{pK}_{\mathrm{a}}$ values of $3.37 \pm 0.09$ and $6.39 \pm 0.25$, suggesting that within the $\mathrm{pH}$ range $2-8$ the radical exists in three differently protonated forms. Both of the two deprotonated forms have absorption spectra which are similar, but not identical, to that of the amine oxidase free radical. All three aminoresorcinol radicals are found to be unstable in the pulse radiolysis experiment and decay on a millisecond timescale.

In the $\mathrm{TR}^{3}$ experiments, radicals from oxidation of 4-AR were generated using triplet duroquinone $\left({ }^{3} \mathrm{DQ}\right)$ which we have previously found useful in the one-electron oxidation of phenols $[15,16]$. Using pump and probe wavelengths of 355 and $450 \mathrm{~nm}$ respectively, the $\mathrm{TR}^{3}$ spectra shown in Figure 2A were measured at $\mathrm{pH}$ 8.0. At this probe wavelength the deprotonated 4-AR radicals, the durosemiquinone $\left(\mathrm{DQ}^{-}\right)$radical anion and ${ }^{3} \mathrm{DQ}$ are all in resonance. With the shortest time delay between pump and probe pulses $(20 \mathrm{~ns})$ the spectrum is predominantly that of ${ }^{3} \mathrm{DQ}$ with bands at 1546,1173 and $447 \mathrm{~cm}^{-1}$ [15]. With increasing time delays between pump and probe pulses, this species decays by reaction with 4-AR and the spectrum becomes dominated by the $1612 \mathrm{~cm}^{-1}$ band $\left(\mathrm{C}=\mathrm{C}\right.$ stretch, $\left.\nu_{8 a}\right)$ of the durosemiquinone radical anion [15]. However, it is seen that this band appears to overlay additional features at both the high and low frequency edges. Spectral subtraction of the component due to the durosemiquinone radical anion, obtained by reduction ${ }^{3} \mathrm{DQ}$ by ascorbate and also shown in Figure 2A, reveals the growing spectrum of the 4-aminoresorcinol radical anion with increasing pump-probe delay as illustrated in Figure 2B. This doubly deprotonated radical anion present at $\mathrm{pH}>6.4$ has a resonance Raman spectrum with dominant bands at 1581 and $1628 \mathrm{~cm}^{-1}$. Following previous assignments [17] these are likely to be $\mathrm{C}-\mathrm{O} / \mathrm{C}-\mathrm{N}\left(\nu_{7 a}\right)$ and $\mathrm{C}=\mathrm{C}\left(\nu_{8 a}\right)$ stretching modes respectively. An additional feature is observed at $1140 \mathrm{~cm}^{-1}$ which may be assigned to a $\mathrm{C}-\mathrm{H}$ bend $\left(\nu_{9 a}\right)$. The low frequency mode at $529 \mathrm{~cm}^{-1}$ is assigned to the $-\mathrm{CCC}$ - bend $\left(\nu_{6 a}\right)$. 

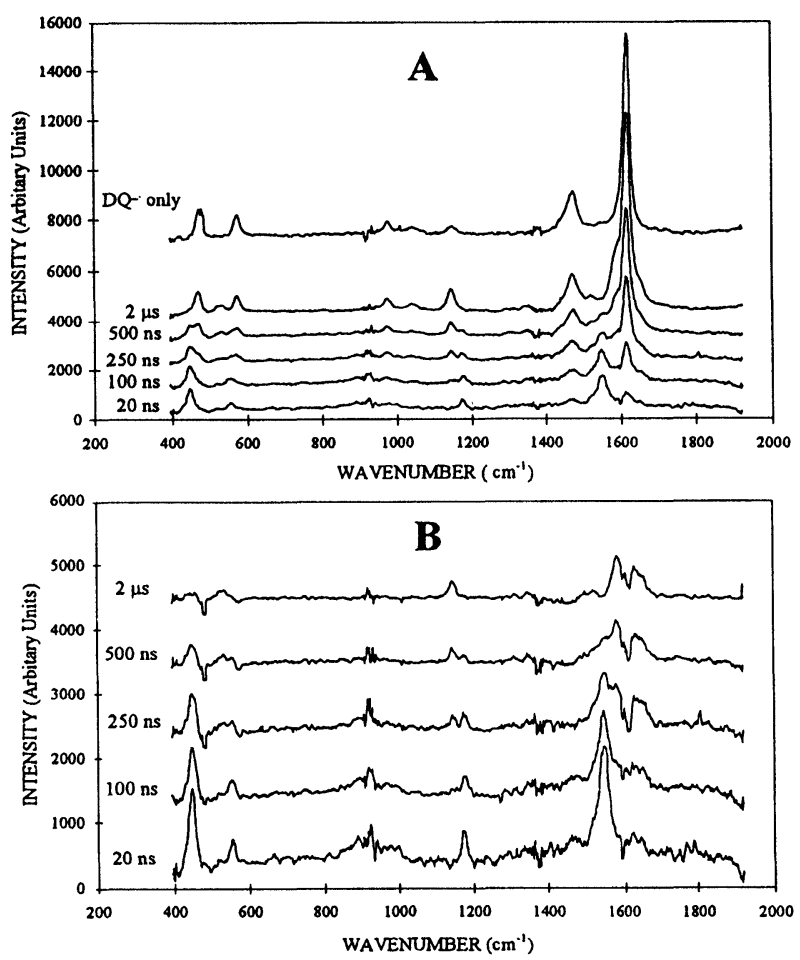

FIGURE 2 Time-resolved resonance Raman spectra obtained from solutions $\left(\mathrm{H}_{2} \mathrm{O} /\right.$ acetonitrile $\left.50 / 50 \mathrm{v} / \mathrm{v}\right)$ of $4-\mathrm{AR}(125 \mu \mathrm{M})$ and duroquinone $(1 \mathrm{mM})$ buffered to pH 8.0 with phosphate $(50 \mathrm{mM})$. Spectra were obtained at the indicated intervals between pump pulse $(355 \mathrm{~nm})$ and probe pulse $(450 \mathrm{~nm})$. Panel A shows spectra obtained after subtraction of the probe-only spectra. The spectrum marked " $\mathrm{DQ} \mathrm{Q}^{-\cdot}$ only" was measured in a solution containing duroquinone $(1 \mathrm{mM})$ and ascorbate $(1 \mathrm{mM})$ also at $\mathrm{pH}$ 8.0. Panel $B$ shows the same spectra after subtraction of the durosemiquinone radical anion $\left(\mathrm{DQ}^{-}\right)$component using the spectrum shown in panel $\mathrm{A}$.

In a similar manner $\mathrm{TR}^{3}$ spectra were obtained for 4-AR radicals at $\mathrm{pH} 1.2$ and $\mathrm{pH}$ 5. The 4-AR radical spectra (after subtraction of appropriate durosemiquinone spectra) at all three $\mathrm{pH}$ values are shown in Figure 3, together with the resonance Raman spectrum of the pea seedling amine oxidase free radical, obtained by anaerobic incubation of the enzyme with benzylamine. At $\mathrm{pH} 1.2$ the resonance Raman spectrum of the 4-AR radical has a dominant peak in the $\mathrm{C}=\mathrm{C}$ stretching region at $1629 \mathrm{~cm}^{-1}$ which was shown by band 


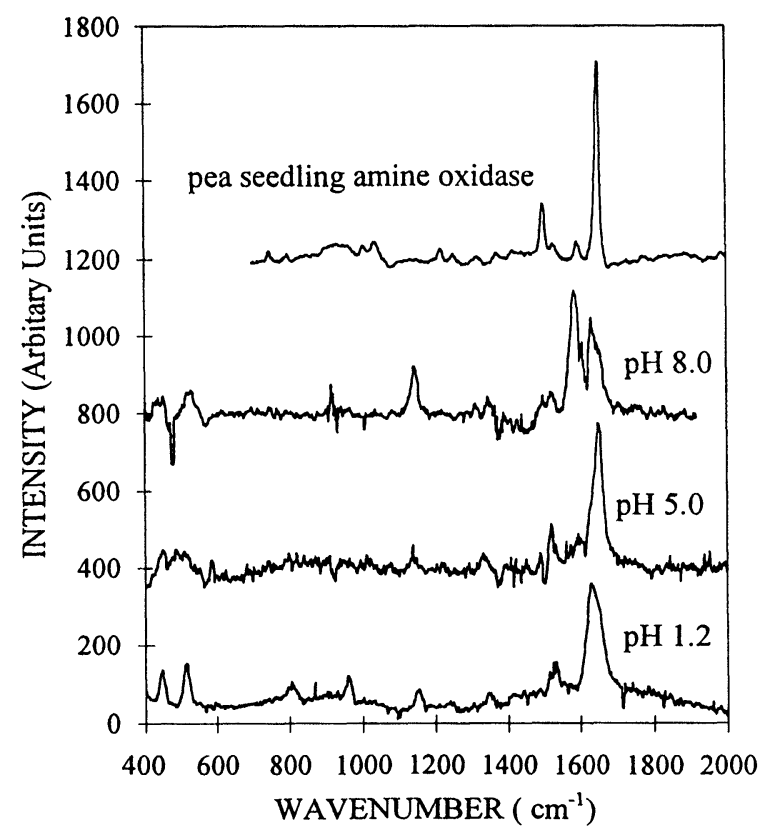

FIGURE 3 Resonance Raman spectra of 4-AR radicals measured at pH 1.2, pH 5.0 and $\mathrm{pH} 8.0$, compared with the spectrum obtained from the radical site in pea seedling amine oxidase after substrate addition under anaerobic conditions.

analysis to contain components at 1627 and $1645 \mathrm{~cm}^{-1}$ in an intensity ratio of approximately $1: 4$. At $\mathrm{pH} 5$ the peak in the $\mathrm{C}=\mathrm{C}$ stretching region shifts to $1648 \mathrm{~cm}^{-1}$, which is very close to our previous determination of $1647 \mathrm{~cm}^{-1}$ for the $\mathrm{C}=\mathrm{C}$ stretching mode in the copper amine oxidase radical [12].

The $\mathrm{pH}$ dependent changes in transient absorption spectra and resonance Raman spectra observed here for the 4-AR radicals are somewhat similar to those observed in radicals formed by one-electron oxidation of 1,2,4-benzenetriol [18] for which the singly and doubly deprotonated forms were virtually indistinguishable by absorption spectroscopy, but which were clearly discriminated between by resonance Raman spectroscopy.

Resonance Raman spectroscopy therefore confirms that there are three differently protonated forms of the 4-AR radical in the range $\mathrm{pH} 1-8$, supporting the identification of two $\mathrm{pK}_{\mathrm{a}}$ 's in the titration 
curve obtained in the pulse radiolysis experiments. The resonance Raman spectra obtained for each protonated form of the 4-AR radicals show that the singly deprotonated form is that which occurs as an intermediate in the catalytic cycle of copper amine oxidases.

\section{Acknowledgements}

Time-resolved resonance Raman experiments were undertaken with the support of EPSRC and BBSRC at the Lasers for Science Facility, Rutherford Appleton Laboratories. Pulse radiolysis experiments were performed at the Paterson Institute for Cancer Research Free Radical Research Facility, Manchester, UK with the support of the European Commission through the Access to Large-scale Facilities activity of the TMR Programme. The experimental help of Drs I. Hamblett and S. Navaratnum with pulse radiolysis experiments is gratefully acknowledged.

\section{References}

[1] Janes, S. M., Mu, D., Wemmer, D., Smith, A. J., Kaur, S., Maltby, D., Burlingame, A. L. and Klinman, J. P. (1990). Science, 248, 981.

[2] Klinman, J. P. and Mu, D. (1994). Annu. Rev. Biochem., 63, 299.

[3] Pedersen, J. Z. and Finazzi-Agro, A. (1993). FEBS Letters, 325, 53.

[4] McCracken, J., Peisach, J., Cote, C. E., McGuirl, M. A. and Dooley, D. M. (1992). J. Am. Chem. Soc., 114, 3715.

[5] Moenne-Loccoz, P., Nakamura, N., Steinebach, V., Duine, J. A., Mure, M., Klinman, J. P. and Sanders-Loehr, J. (1995). Biochemistry, 34, 7020.

[6] Dooley, D. M., McGuirl, M. A., Brown, D. E., Turowski, P. N., McIntyre, W. S. and Knowles, P. F. (1991). Nature, 349, 262.

[7] Parsons, M. R., Connery, M. A., Wilmot, C. M., Yadav, K. D. S., Blakely, V., Corner, A. S., Phillips, S. E. V., McPherson, M. J. and Knowles, P. F. (1995). Structure, 3, 1171.

[8] Kumar, V., Dooley, D. M., Freeman, H. C., Guss, J. M., Harvey, I., McGuirl, M. A., Wilce, M. C. J. and Zubak, V. M. (1996). Structure, 4, 943.

[9] McGuirl, M. A., McCahon, C. D., McKeown, K. A. and Dooley, D. M. (1994). Plant Physiol., 106, 1205.

[10] Steinebach, V., de Vries, S. and Duine, J. A. (1996). J. Biol. Chem., 271, 5580.

[11] Bellelli, A., Brunori, M., Finazzi-Agro, A., Floris, G., Giartosi, A. and Rinaldi, A. (1985). Biochem. J., 232, 923.

[12] Johnson, S. A., Bisby, R. H., Tavender, S. M. and Parker, A. W. (1996). FEBS Lett., 380, 183.

[13] Kaim, W. and Rall, J. (1996). Angew. Chem. Int. Ed. Engl., 35, 43.

[14] Mure, M. and Klinman, J. P. (1993). J. Am. Chem. Soc., $115,7117$.

[15] Bisby, R. H. and Parker, A. W. (1995). J. Am. Chem. Soc., 117, 5664.

[16] Bisby, R. H., Johnson, S. A. and Parker, A. W. (1996). Free Rad. Biol. Med., 20, 411. 
[17] Tripathi, G. N. R. (1989). In: Time-resolved Spectroscopy, Eds. Clark, R. J. H. and Hester, R. E. (Wiley, New York), pp. 157-218.

[18] Qin, L., Tripathi, G. N. R. and Schuler, R. H. (1987). J. Phys. Chem., 91, 1905. 